\title{
Hacia una epistemología del concepto de símbolo
}

\author{
TOWARDS AN EPISTEMOLOGY OF THE CONCEPT OF SYMBOL
}

Dra. Salomé Sola-Morales (salome.sola@usach.cl) Escuela de Periodismo, Universidad de Santiago de Chile (Santiago, Chile)

\begin{abstract}
This essay aims to analyse the theoretical and epistemological foundations of the symbol and their representations. First of all, we have explored its ontological scope. Secondly, we have highlighted its presence in everyday life. Thirdly, we have underlined the importance of the interpretation when addressing their multiple senses. And fourthly, we have expressed its social and cultural importance. The thesis here is that the symbolic is a structural condition of humankind, such as a being of mediation. Therefore we claim an epistemological perspective that takes into consideration this notion, key to understanding human being and psychosocial reality.
\end{abstract}

Key-words: symbolic, symbols, mediations, self, daily life.

\section{Resumen}

El presente ensayo tiene como objetivo principal analizar los fundamentos teórico- epistemológicos del concepto de símbolo y sus formas de representación. En primer lugar se delimitó el alcance ontológico de esta noción. En segundo se destacó su presencia en la realidad cotidiana. En tercero se subrayó la importancia de la interpretación a la hora de abordar sus múltiples sentidos y, en cuarto, se manifestó su relevancia social y cultural. La tesis que aquí se sostiene es que lo simbólico es una condición estructural del ser humano, como ser de mediaciones. Por ello reivindicamos una perspectiva epistemológica que tenga presente esta noción, clave para comprender al ser humano y la realidad psico-social en la que se inserta.

Palabras clave: simbólico, símbolos, mediaciones, ser, realidad cotidiana.

\section{Introducción}

Con frecuencia, sobre todo, en el ámbito cultural occidental, el término símbolo (symbolon) ha poseído usos y aplicaciones heterogéneas en los diversos sistemas sociales, dado que es multivalente y ambiguo en sí mismo, como veremos. Y como algunos autores han señalado, todavía hoy continúa siendo una noción evasiva y oscura. Precisamente por eso, en este ensayo no plantearemos ninguna definición única o axiomática del término, ya que simplificaríamos o limitaríamos su potencialidad. Por el contrario, lo que haremos será clarificar el alcance epistemológico de este concepto, muchas veces ignorado e infravalorado, y subrayar la necesidad epistemológica de tenerlo presente.

El cartesianismo suscitó el triunfo del signo sobre el símbolo -y del concepto sobre la imaginación-, ya que se consideraba a los segundos inductores de errores. Recordemos que en la primera parte del Discurso del Método, Descartes señaló la importancia de distinguir entre lo verdadero y lo falso y al referirse a las opiniones subrayó la 
necesidad de tener "casi por falso todo lo que no fuera más que verosímil" (1939:6). Es decir, a su juicio, todo lo que no atienda a un razonamiento lógico carece del estatuto de verosimilitud. Pero no podemos olvidar que muchas de las certidumbres humanas también pueden construirse en base a emociones, sentimientos o vivencias subjetivas que no pueden ser comprendidas o abordadas exclusivamente desde esta perspectiva. De hecho, muchos de los interrogantes fundamentales aún permanecen irresolutos y no han sido aún respondidos atendiendo al método hipotético-deductivo.

Es más, como ha sugerido Albert Chillón, "el logocentrismo cartesiano ensalza el concepto y posterga la imagen, pero al actuar así se niega a ver, no sólo que el concepto nace sin remedio como imagen y vive alimentándose de ella, sino que concepto e imagen no son ni pueden ser más que las dos facetas del símbolo y del rasgo más propio del intelecto humano, que es a no dudarlo la función de simbolización" (2000:141). Aquí el autor se refiere a la necesaria coimplicación entre concepto e imagen y se posiciona en contra de los dualismos que sólo muestran un aspecto de la realidad humana. De hecho, a nuestro juicio, la capacidad de simbolizar o función de simbolizar es inherente a la condición humana ya que se encuentra en la base del pensar mismo. Esto se debe a que pensamos en y mediante símbolos, utilizamos imágenes y palabras que nos permiten evocar ideas, expresar sentimientos, comunicarnos e interactuar con otros y comprender el entorno circundante. Por eso, se podría considerar que el símbolo es, antropológica y ontológicamente, el fundamento mismo del pensamiento humano, como trataremos de demostrar a lo largo del presente ensayo.

Desde nuestra perspectiva, como veremos a continuación, el conocimiento, la cultura colectiva, la realidad compartida y los sujetos son y se comportan de manera eminentemente simbólica, en tanto se expresan de manera figurada. Dicho con otras palabras, los sujetos y los grupos emplean mediaciones para hacerse inteligibles. Visto así, todo acceso a la realidad humana está mediado por algo, sea el lenguaje o sea una imagen. De hecho, la comprensión del entorno circundante nunca es literal o directa, ya que los seres humanos han de apoyarse o utilizar diferentes mediaciones para comprender la realidad. Los símbolos serían por tanto mediaciones que les permiten conectar o poner en sintonía el interior de la conciencia humana y el exterior de la realidad en sí.

El ser humano necesita estas mediaciones, palabras, imágenes, símbolos para poder comprender el mundo que habita y comunicarse en él. Gracias a estos diversos artefactos semióticos y comunicativos puede relacionarse con el mundo e interactuar con los demás sujetos y grupos. Así, por ejemplo, mediante una palabra, una exclamación, un gesto, un ícono o una creación artística el hombre puede comunicar un sentimiento, una emoción o una vivencia de la realidad.

Ahora bien, no podemos olvidar que "comunicar" no significa expresar literalmente la vivencia, ya que es imposible obtener algo idéntico a la experiencia misma. De hecho, como señala Chillón, "el mundo simbólico del hombre es, entonces, no tanto obra de imitación y representación (mímesis) de la muda naturaleza (physis) cuanto de figuración y creación (poiesis) de la expresiva realidad humana" (2000:143). Y esta realidad y sus vías de expresión son sustantivamente imaginativas, ya que están configuradas, creadas y mediadas gracias a las "formas simbólicas", anteriormente mencionadas. Este último concepto, el de forma simbólica, acuñado por Ernst Cassirer (1998), es entendido aquí como una expresión significativa particular. Mientras que la materia es estructural y generalmente tiende a la estabilidad, la forma expresa el matiz variable del símbolo particular o concreto. Así, los sujetos y los grupos utilizan artefactos significativos históricos y cambiantes gracias a los cuales pueden comprender, definir e interpretar el mundo y la realidad circundante. Podríamos decir así que el ser humano construye significativamente su mundo mediante o a través de imágenes, palabras o símbolos. 
Los símbolos son capaces de otorgar valor significativo y comprensivo a los hechos o a la realidad en sí. Gracias al uso de elementos figurativos e imágenes los seres humanos pueden otorgar sentidos, lo cual les permite por una parte comunicar, expresar y definir la realidad circundante y por otra comunicarse, expresarse y definirse en ella, como iremos detallando.

En este sentido, reivindicamos como han hecho numerosos autores -como Ernst Cassirer, Gilbert Durand, Hans Blumemberg o Lluís Duch- una visión integradora de los modos arquetípicos, simbólicos y míticos de pensar donde la imaginación y la razón se complementen y den lugar a una comprensión más completa del ser humano. Ya que el predominio de una de estas facetas puede reducir la riqueza humana a un mono-discurso totalizador o a una crisis de sentido (estamos pensando en algunas latrías como el culto al mercado, a la ciencia u a otros fundamentalismos, que proponen el predominio de las lógicas más devastadoras al servicio de la imaginación).

Un autor que ha sugerido la integración o co-implicación de algunos de estos dualismos tradicionalmente separados y enfrentados (imaginación-razón; subjetividad-objetividad, entre otros) es Marcel Gauchet. A su juicio "no estamos encerrados en los límites del conocimiento objetivo" (2003:35). En este sentido es importante recalcar que la imaginación y el símbolo son categorías abiertas a descubrir nuevos sentidos que complementan a la razón de forma integradora. Por ello, el pensamiento y la realidad humana no pueden ni deben ser reducidos ni al pensamiento logocentrista (que enfatiza en el logos o el concepto), pero tampoco a la imaginación (que otorgaría una mayor importancia al símbolo o la imagen). A este respecto, y como iremos argumentando en lo sucesivo, creemos necesario plantear un enfoque dialéctico que permita integrar ambas facetas de lo humano.

\section{Fundamentos ontológicos de lo simbólico}

Cualquier estudio ontológico sobre el ser humano, que podría iniciarse con la clásica pregunta antropológica “¿quién soy?", debería tener como premisa que el yo vive en un sistema o universo simbólico y, que en rigor, es yo en virtud de dichos símbolos. Esto quiere decir que la misma tarea de construcción del sujeto necesita símbolos, palabras, imágenes y mediaciones para así adquirir sentidos. De hecho, gracias al sistema o red de símbolos en que el ser humano nace, crece y se desarrolla puede construir y comprender el universo y la realidad en la que habita y, como es evidente, dar significación a su propia experiencia y a sus relaciones con los demás. No olvidemos que este sistema o red de símbolos desde el cual el sujeto comprende la realidad es eminentemente cultural y, por tanto, le viene ya implícitamente dado. Nacemos, por tanto, en un marco de referencia desde el que nos situamos, definimos y comunicamos y compartimos símbolos con los demás miembros de nuestra cultura desde el nacimiento hasta la muerte.

Inicialmente debe establecerse una diferencia entre lo simbólico y los símbolos, distinción que si bien puede parecer inicialmente exigua para nosotros es crucial. A nuestro juicio, mientras que lo simbólico, en cuanto tal, es una condición estructural de la naturaleza humana, los símbolos son de carácter histórico, ya que son rearticulados en función de los diversos contextos existenciales. Esto quiere decir, que los símbolos podrán cambiar en cada época en función de diferentes modas o tendencias y explica, también, por qué en diferentes culturas o países existen símbolos diferentes. Pero, al mismo tiempo pone de manifiesto que lo simbólico, en singular, como tendencia, es inherente a la condición humana. Se podrán utilizar símbolos diversos, pero el hombre no puede dejar de simbolizar; igual que no puede dejar de comunicar aunque su forma de hacerlo sea el silencio.

Es preciso anotar que realizamos esta distinción basándonos en el modelo interpretativo iniciado por el antropólogo Lluís Duch en su tesis doctoral Ciencia de la religión y mito (1974) y desarrollado en su obra Historia y estructuras religiosas (1978). Para el investigador es necesario mantener la tensión estructura-historia. Y aunque éstas sean dos 
categorías que corresponden a diferentes órdenes, sólo coimplicadas dan muestra de la verdadera humanidad del hombre. Para el autor, el ser humano no puede ser definido exclusivamente en virtud de su esencia, es decir, aquello que permanece y no cambia; ni en virtud de su existencia, es decir, su experiencia o vivencia de la realidad. Por eso, el investigador hace especial hincapié en que a un nivel epistemológico no es recomendable privilegiar, por ejemplo, la permanencia frente a la transformación. Y así siempre se darían ciertas constantes en los cambios, y del mismo modo, los cambios siempre harían referencia a una cierta estabilidad. Por ejemplo, estamos pensando en la compleja noción de personalidad que, muchas veces, es definida como algo estructural y estable y otras como algo histórico y, por tanto, cambiante en cada etapa vital. A la luz del modelo interpretativo propuesto, ninguna de estas aproximaciones, sin embargo, sería muy completa, ya que la personalidad siempre mantendría algunos elementos esenciales; pero al mismo tiempo iría variando en función de las circunstancias histórico-vitales.

En definitiva, el modelo interpretativo que hemos descrito puede ser aplicado en relación a diferentes cuestiones antropológicas y, en este caso, es muy útil para comprender el concepto de símbolo, que como venimos explicando líneas atrás, desde nuestra perspectiva, no es ni estructural, ni histórico, sino un artefacto o mediación que se encuentra en una situación intermedia entre la continuidad y el cambio. A saber, mientras que la estructura proporciona temas a priori (lo simbólico, en este caso), la historia articula dichos temas a posteriori (los símbolos concretos). Tengamos presente que los a priori se tratan de los elementos propios de la condición humana, que están ahí y no pueden modificarse ni cambiarse; mientras que los a posteriori se tratan de las diferentes articulaciones históricas de los primeros.

La tensión o coimplicación entre estructura e historia de la que venimos hablando nos permitirá, fundamentalmente, evitar reduccionismos o simplificaciones ante el abordaje de complejos procesos o conceptos como símbolo, como se explica a continuación siguiendo la propuesta de Duch. A su juicio, si reducimos lo estructural a lo histórico tenderemos al reduccionismo o al relativismo, ya que sólo prestaremos atención a la existencia, fruto exclusivo de las coyunturas económicas, sociales o políticas. Esta tendencia relativista es la que entiende que nada permanece y todo está sujeto al cambio. Y justamente a raíz de este planteamiento sólo lo novedoso o lo efímero tiene valor (de ahí surgen numerosas latrías, como el culto al cuerpo, el mercado o la tecnología, como se decía antes).

Por el contrario, si limitamos lo histórico a lo estructural tropezaremos con el esencialismo, ya que no tendremos en cuenta las peculiaridades culturales e históricas de cualquier situación o proceso (Duch 1978). A la luz de este planteamiento esencialista, por ejemplo, todos los miembros de una cultura, un país o una etnia, independientemente del momento histórico en el que vivan o de su manera de actuar serían idénticos. Ya que primaría el "ser" por encima del "hacer". Este reduccionismo podría traer consigo la circulación de numerosos estereotipos y otros prejuicios excluyentes.

Por eso, al preguntarnos si los símbolos son esencia o existencia, no dudaremos en matizar que se encuentran en un terreno intermedio. Dicho en pocas palabras, la capacidad simbólica sería una condición estructural al ser humano (permanente y esencial) que al mismo tiempo adquiriría formas cambiantes y sujetas a la existencia y la historicidad misma. Esto se debe a que como hemos apuntado, a juicio de Lluís Duch, a un nivel estructural, el hombre tiende a simbolizar. Únicamente hemos de tener presente que en función del momento socio-histórico y cultural el ser humano utilizará unos símbolos u otros. Además, los símbolos para representar diferentes cuestiones podrán ser muy sencillos o muy complejos, ser artefactos naturales o elementos artificiales bien construidos y elaborados. Desde el uso de un color en una prenda de vestir, la muestra de un objeto dado o la participación en un ritual de gran complejidad, todo este tipo de prácticas pueden simbolizar la misma cosa de formas diferentes. 
Precisamente esta condición inherente y ambigua del concepto en cuestión (permanece porque es estructural siempre simbolizamos sería la máxima- y cambia porque en cada época se simboliza de forma diferente) es la que ha llevado a numerosos autores a afirmar que la simbolización (capacidad simbólica) es el atributo específico que hace al ser humano, humano. Con razón Ernst Cassirer sostiene que el hombre es un animal simbólico, que puede construir potencialmente infinitos mundos simbólicos alternativos, o según Mircea Elíade es un homo symbolicus, capaz de ir más allá de sí mismo.

Además, los símbolos no son creaciones irracionales e independientes de la psique y aparecen en toda clase de manifestaciones tales como los pensamientos o los sentimientos, como ha sugerido Carl Gustav Jung, para quien el símbolo siempre representa algo más que su significado evidente e inmediato: "cuando la mente explora el símbolo se ve llevada a ideas que yacen más allá del alcance de la razón" (1995:20). Esto explicaría, por ejemplo, por qué los símbolos responden a una necesidad innata del ser humano por conocer lo desconocido y representan aquello que no se puede definir o comprender del todo, ya que a su juicio los símbolos representan "algo vago, desconocido $u$ oculto para nosotros" (1995:20). De manera que se sitúan en un terreno intermedio rellenando espacios vacíos de sentido o lugares desconocidos, si preferimos llamarlos así. Dicho de otro modo, los símbolos podrían cumplir la función de exhibir las realidades más profundas del ser (Elíade) si lo planteamos desde una perspectiva metafísica.

Justamente, el hombre y la mujer son los únicos seres que además de tomar parte en el proceso de simbolización llegan a ser conscientes de él. Esta toma de conciencia de la propia capacidad simbolizante recuerda, sin duda, a la definición del anthropos propuesta por Helmuth Plessner, según la cual éste es un ser 'excéntrico'. A sus ojos, los humanos disponen de la posibilidad de "tomar distancia respecto de sí mismos" (1991:31) o, lo que es lo mismo, son capaces de descentrarse, tomar distancia y desarrollar una conciencia de sí o auto-conciencia. Esta capacidad analítico-simbólica es la que permite a los seres humanos reflexionar acerca de sí mismos y de sus propias vivencias cotidianas. Mientras que el animal actúa movido por impulsos que no es capaz de analizar a posteriori, el ser humano puede dar un rodeo significativo acerca de sus vivencias, sus maneras de actuar e, incluso, ser auto-crítico. $Y$ precisamente esta auto-critica se basa en comparaciones respecto a pautas simbólicas y culturales que le son instituidas mediante la socialización. Por eso, la tarea de simbolización no es individual es primordialmente compartida y debe ser entendida no sólo como el modus vivendi y operandi propio de los humanos (Duch), sino como el funcionamiento estructural de la comunidad. Tanto el individuo como el grupo, por tanto, se caracterizan por su necesidad de integrar su vida empírica mediante símbolos.

Mas ¿por qué se ven obligados los individuos a utilizar estas fórmulas en su vida cotidiana? Según nuestro parecer, el ser humano siempre está dotado de una perspectiva subjetiva, social, cultural y, por tanto, sólo puede aproximarse a la realidad a través de alguna mediación (sea ésta lingüística, visual, corporal...) y siempre desde un marco de referencia socio-cultural en el que se inserta.

\section{Un universo simbólico y una realidad mediada}

Quizás fuese el romántico Georg Friedrich Creuzer, discípulo de Schiller, el que primero y mejor expresó la importancia del símbolo, al decir que éste "representa el camino más corto para alcanzar la realidad" (Creuzer en Duch 2002a:369). Para Creuzer, los símbolos no son explicables ni racionalizables y podrían ser definidos como aquello que no puede ser plena ni cabalmente comprendido por el concepto. Es decir, como este último no es capaz de definir totalmente la realidad es cuestión, el símbolo ofrece una aproximación complementaria más accesible. Esto es especialmente significativo en el terreno de las emociones. Pensemos, por ejemplo, cómo un concepto como "alegría" hace alusión a un estado determinado conocido por todos. Pero, también es cierto, que la alegría es mucho más que la definición que reporta ese concepto. No obstante, tratemos de pensar en las diferentes maneras en que 
podría simbolizarse esta emoción. Es más habitual que las personas representen o comprendan su estado de alegría mediante formas simbólicas: una sonrisa es una buena muestra de ello, si pensamos en la más evidente. Ahora bien, esta última que podría ser una expresión más completa de la emoción "alegría" resulta inherentemente ambigua, ya que puede significar muchas más cosas y precisa, por tanto, de una interpretación.

De hecho, como acertadamente ha afirmado Duch, mientras que el orden conceptual hace referencia a la generalización abstracta, a la objetividad o a la fijación unívoca; el orden simbólico, por el contrario, es históricocontextual, cultural y equívoco (Duch) ya que es vivenciado por cada persona o por cada grupo cultural de un modo u otro. Así, el concepto anteriormente mencionado encierra en sí mismo un significado dado, el gesto simbólico, que por el contrario deberá ser interpretado a la luz de un contexto comunicativo, socio-cultural e histórico. Esto no significa en ningún caso que lo simbólico sea erróneo o falso, sino que es mutable y está sujeto a las variaciones espacio-temporales. Es por eso que en cada contexto la sonrisa podría ser interpretada de un modo y otro. Este hecho nos induce a considerar que los símbolos no remiten a nada fijo y por ello, son fundamentalmente ambiguos, como iremos detallando en lo sucesivo.

Ahora bien, algunas de las premisas más relevantes que configuraron el pensamiento de Creuzer y le dieron solidez también se hallan en Ernst Cassirer, para quien el hombre no vive "en un puro universo físico sino en un universo simbólico" (1963:47). De manera, que los símbolos son la materia esencial para construir el mundo humano y habitar en él. A la luz de sus planteamientos, el sujeto se halla inmerso en un universo simbólico en el que se encuentra envuelto en formas lingüísticas, imágenes artísticas, símbolos míticos o ritos religiosos y no puede ver ni conocer nada si no es a través de este medio. Dicho de otro modo, más que vivir en un mundo de crudos hechos o de hechos brutos, como él diría, el hombre "vive, más bien en medio de emociones, esperanzas y temores, ilusiones y desilusiones imaginarias, en medio de sus fantasías y sus sueños" (Cassirer 1998:48).

Así, tanto de una manera teórica como práctica, el sujeto se encuentra con representaciones, significaciones e interpretaciones, por medio de las cuales comprende y participa en la vida cotidiana. Precisamente el triunfo del positivismo, que mencionábamos al inicio de este artículo fue el que desterró la imagen, la emoción y el símbolo como formas de acceso a la realidad, porque eran consideradas erróneas ya que se consideraban ingredientes de la subjetividad. Pero no podemos olvidar que la comprensión de la realidad es un proceso situado y vivenciado por un sujeto que la experimenta y la observa y, al mismo tiempo, la construye. Y la presencia de este observador, como diría Humberto Maturana, pone de manifiesto que la realidad no es independiente de quien la mira, efectúa y siente, sino que su construcción se produce en una necesaria coimplicación con los sujetos.

Al mismo tiempo este acceso o construcción de la realidad será siempre mediado por lo simbólico y a su vez articulado por lo conceptual. Es decir, que ambas formas de comprensión conviven y se complementan.

\section{Los símbolos como mediaciones}

Hemos afirmado que los símbolos funcionan como mediadores y por tanto, pertenecen a un terreno intermedio, ya que representan algo que va más allá de ellos mismos. Valga expresar la importancia y sentido que damos al concepto de mediación. A nuestro juicio los símbolos se inscriben dentro de las mediaciones, entendidas como relaciones capaces de transformar las prácticas comunicativas, los movimientos sociales, las diferentes temporalidades y la pluralidad de matrices culturales (como diría Martín Barbero). De este modo, los símbolos en tanto mediaciones y representaciones nos permiten acceder al conocimiento del entorno circundante y al autoconocimiento del sí y de los otros. Esto quiere decir que funcionan como artefactos dotados de sentido que facilitan a los individuos y los grupos comprender la realidad cotidiana y auto-definirse en ella y definir a los otros. Dicho de otro modo, los sujetos 
y los grupos más que construir el mundo a través o gracias a símbolos diversos, lo construyen en y con ellos. Esto vendría a significar que los símbolos no son únicamente una herramienta cultural, comportamental o pauta procedimental aprehendida socialmente, sino que además se encuentran insertos estructuralmente en el acto mismo de pensar.

Valga mencionar que las formas simbólicas tienen la capacidad de expresar tanto la realidad externa (los objetos del orbe físico) como la interna (los pensamientos o ideas del orbe psíquico). Desde esta perspectiva, el símbolo tendría una doble función: primero, la de marcar el camino para llegar a uno mismo y segundo la de expresar y definir el universo o entorno circundante. En este sentido, es importante matizar que los símbolos no tienen una entidad física propiamente dicha, tal y como ha sugerido Cassirer. De hecho, no son la propiedad de la cosas ni son rígidos o estáticos; por el contrario, son variables y móviles, y tienen capacidades significativas o designativas. Lo cual quiere decir que no encierran una única definición o varias definiciones en sí mismos, como podría ser el caso de un concepto cualquiera. Por el contrario, los símbolos siempre permanecen abiertos y deben ser interpretados a la luz de un contexto determinado y dentro de un marco cultural dado. Lo que en un país puede simbolizar una cosa en otro puede resultar otra, por ejemplo. Este el caso, por decir, del hiyab o velo islámico, símbolo que representa en los países árabes una seña de identidad religiosa y femenina y que, en algunos países occidentales, es interpretado como una forma de dominación masculina.

Es más, los símbolos poseen un valor funcional que es el de otorgar o poseer sentidos, ya que no son un objeto en sí mismo, sino una ley, entendida como una forma (Cassirer), que permite el descubrimiento de diversos campos de la experiencia. Esto quiere decir que el símbolo siempre mantiene una relación con la realidad variable y cambiante, ya que se encuentra unido a la praxis, por eso el hiyab puede significar en un país liberación y en otro opresión. Y este es, precisamente, uno de los aspectos más relevantes de su contribución: la conjunción establecida entre el aspecto formal del símbolo, su significación y el ámbito de la experiencia humana y su interpretación.

\section{¿Una hermenéutica del símbolo?}

Podría decirse, por tanto, que las formas simbólicas son capaces de configurar las relaciones del hombre con el mundo en tanto dan sentido a la experiencia. El hecho de que estas formas no sean estables y siempre se muestren abiertas a la interpretación es el que nos hace afirmar que los símbolos son polisémicos, ambivalentes y fundamentalmente ambiguos, como ya anunciamos anteriormente. No obstante, aunque lo símbolos puedan ser interpretados, nunca podrán serlo del todo, como bien ha sugerido Carles Mèlich (1996:63) ya que no hay, ni puede haber una 'hermenéutica absoluta' del símbolo. Esto se debe a que lo símbolos siempre están abiertos a nuevas valencias o decodificaciones diversas (Duch y Chillón 2012:188), por lo que no sería posible interpretarlos totalmente o por vez última. De hecho, si un símbolo es interpretado del todo o adquiere un sentido último o definición axiomática pasaría a convertirse en un mero signo.

Precisamente, como ha expresado acertadamente Duch (2010:187), la característica fundamental del ser humano es la ambigüedad, consecuencia inmediata de su finitud constitutiva y causa directa de su relación con el símbolo: "Porque es fundamentalmente ambiguo, el ser humano se ve obligado a vivir y morir en la esfera de los símbolos". Por esta razón, la ambigüedad es el atributo por excelencia del símbolo, dado que "al contrario que el 'mero' signo, se mantiene constantemente abierto a nuevas posibilidades de relación con la realidad simbolizada" (2002b:44). Igualmente se encuentra siempre abierto a nuevas resignificaciones, de modo que el sujeto-intérprete adquiere un lugar notorio en la interpretación de los símbolos. 
Otro autor que ha subrayado el carácter intermedio de las formas simbólicas es el ya citado Ernst Cassirer. Para él, los símbolos son capaces de mediar entre los dualismos que encuadran el pensamiento tradicional (bien-mal, mentecuerpo o interno-externo) y la experiencia de los seres humanos. En su opinión, el verdadero concepto de lo simbólico no puede adaptarse a las tradicionales clasificaciones o dualismos metafísicos, sino que debe superar y romper sus marcos. Este antidogmatismo es una de las claves de nuestra propuesta. Así, lo que necesitamos retener es que el símbolo no es 'lo uno o lo otro' sino que representa 'lo uno en lo otro' y 'lo otro en lo uno'. Las formas simbólicas serían aquí, no ya imitaciones de la realidad, sino órganos que permiten construir la realidad humana propiamente dicha. De esta manera, la función primera del símbolo sería la de convertir, transformar, trasladar de un universo a otro una realidad (subjetiva) que precisa ser objetivada u objetivable, o lo que es lo mismo, transformar las meras vivencias sensibles en experiencias. Y aquí, como es evidente, la interpretación y el legado de la hermenéutica es clave.

En este sentido, cabe insistir que para nosotros un acceso total a la realidad es una tarea difícilmente alcanzable, puesto que ésta no existe en tanto sustancia única o acabada, sino como proceso 'in fieri'. La labor del hombre consistiría, por tanto, en acotar y rodear un terreno impreciso-de aquí la palabra experiencia, que viene de ex-perior: transitar alrededor-del que nunca podrá tener más que una vaga impresión gracias a los símbolos. Es decir, el acceso a la realidad será siempre mediante formas polisémicas que nos permiten demarcar y otorgar sentido a la realidad circundante, situarse y comprenderse en ella.

Pero ¿cómo accedemos a estas impresiones o realidades cotidianas propias y ajenas? Tal y como menciona Duch (2004:91): “Fundamentalmente lo humano consiste en una construcción simbólica y social de la realidad que posibilita la instalación del ser humano en su mundo cotidiano; una instalación que comporta constantes procesos de interpretación de su entorno físico y humano o lo que es lo mismo: en continuas contextualizaciones a tenor de los cambios que impone la propia biografía de los seres humanos".

Este continuum interpretativo se debe a que el símbolo permanece siempre abierto, de manera que el sujeto debe desvelar algo que no responde a la evidencia racional. De ahí, que sea necesario dar cabida a la imaginación como fuente creadora y al pensamiento arquetípico, mítico y simbólico. Es más, como apuntó Jung (1995:55), el símbolo siempre representa algo más que su significado evidente e inmediato. Es decir, va más allá de lo que se puede afirmar en una primera instancia. De manera que el símbolo “nunca es 'explicado' de una vez para siempre, sino que ha de ser descifrado continuamente, de la misma manera que una partitura musical nunca es descifrada para siempre, sino que sugiere una ejecución siempre nueva" (Duch 2002a:158).

Puesto que no tenemos un acceso directo o inmediato a la realidad necesitamos utilizar símbolos que median entre el mundo y el hombre. En este sentido, lo simbólico funciona como un médium entre lo conocido y lo desconocido, entre la presencia y la ausencia o dicho de otro modo "hace mediatamente presente lo que es inmediatamente ausente" (Duch 2002b:224). Esto se debe a que "las ausencias, los vacíos son parte integrante e irrenunciable de la construcción del mundo humano y de la vivencia en él" (Duch 2010:233). A sus ojos, lo que caracteriza el trabajo del símbolo es la aptitud que éste tiene para establecer compatibilidades entre mundos diferentes y desconocidos entre sí a través de los que ha de moverse, pensar y vivir el ser humano. Así, los símbolos permiten trascender los límites -de lo inefable y lo incomprensible- y hacer presente o acercar aquellas partes de la realidad que nunca estarán a nuestra disposición.

De hecho, gracias al símbolo los humanos podemos ir más allá y "llenar nuestros vacíos e iluminar nuestras sombras" (Duch 2010:224) aunque sea en forma de ausencia. Ya que el hombre se encuentra instalado continuamente en la cuerda floja y entre la continuidad y el cambio. Como ha sugerido el investigador, el trabajo simbólico permite abrir 
nuevos horizontes, actualizar en cada presente las “las inagotables posibilidades del 'ausente' pasado y futuro -'el ya-no presente' y 'el todavía-no presente'-, que llega a ser provisionalmente actual” (Duch 2010:233).

En definitiva, los símbolos funcionan como un lugar de encuentro -o modo de comunicación- entre los universos de la familiaridad y los de la extrañeza, entre lo ausente y lo presente, entre el pasado, el futuro y el presente; y sobre todo, sirven al ser humano para vencer la confusión y la contingencia que éste experimenta en forma de decadencia física -mortalidad- a causa del irrefutable paso del tiempo. De manera que el símbolo es un artefacto que permite al ser humano suplir las deficiencias de su propia humanidad. Por ello, podría decirse que lo simbólico tiene la capacidad de invocar y evocar, de rememorar y de anticipar o, lo que es lo mismo, de tender puentes entre lo ausente y lo presente. Mediante el recurso a lo simbólico, los seres humanos pueden hacer coincidir el ayer, el hoy y el mañana o dar existencia a lo inexistente, funciones que son fundamentales para comprender el anthropos.

\section{Acervo social y cultural de los símbolos}

Pero lo simbólico también desempeña una función socializadora fundamental, como bien han manifestado Alfred Schütz o Peter L. Berger y Thomas Luckmann, por ejemplo. Y al mismo tiempo ocupa un lugar central en la cultura, como han sugerido Victor Turner o Clifford Geertz (1981:215) al afirmar que "la cultura es un sistema de símbolos, en virtud de los cuales el hombre da significación a su propia experiencia”.

De hecho, estas formas de expresión tienen un papel crucial en todos los ámbitos de la vida corriente y de la interacción diaria entre los individuos y los grupos, ya que les permiten representar, traducir e interpretar constantemente lo que ocurre a su alrededor y otorgar sentidos a la existencia humana. En palabras de Duch (2004:24), "el existir humano, que jamás puede eludir el empalabramiento de la realidad (el lenguaje), es sencillamente una manipulación (en el sentido mejor y en el peor de este vocablo) con símbolos". Los símbolos aparecen aquí como creaciones imaginativas que toman consistencia en forma de palabras e imágenes. De ahí la importancia del lenguaje y la semiosis en general, como formas de manifestación y constitución del sujeto, que sirven para comprender la realidad.

Podría afirmarse, por tanto, que estas mediaciones y representaciones nos permiten acceder al conocimiento del entorno circundante o, lo que es lo mismo, a relacionarnos en él. Desde una perspectiva antropológica, la relacionalidad constituye el centro operativo del hombre como ser de mediaciones. Y es que lo simbólico refuerza y establece vínculos de pertenencia y autorreferencia entre los diferentes grupos humanos, legitimando a su vez la construcción del nosotros y otros.

Llegados así al fin de nuestra aproximación epistemológica acerca del símbolo, nos gustaría remarcar, tal y como propone Duch (2010:167), que el símbolo puede ser un factor estructurador y reconciliador de la humanidad ya que permite trasladar y asir realidades inabarcables: "Pero también con una relativa frecuencia -tal y como pone de relleno la trágica historia del siglo XX- puede convertirse en un elemento muy peligroso, que puede desencadenar amenazas, angustia y frustraciones con una gigantesca fuerza destructora y pervertidora de las profundidades más íntimas del individuo y de las colectividades humanas".

En este sentido debemos entender el símbolo en sus dos facetas: en positivo, como un artefacto que guarece la condición humana; y en negativo, ya que puede convertirse en un 'envenenador' de la vida privada y pública de los individuos y los grupos. En definitiva, el hombre como animal simbólico y ser de mediaciones nunca termina o llega a establecer relaciones inmediatas o directas con la realidad, sino que, como dice Duch (2010:272), "siempre y 
alrededor se ve constreñido a relacionarse con su entorno de manera indirecta, oblicua, con unos rasgos fundamentalmente metafóricos".

\section{Conclusiones}

Para concluir y en atención a los planteamientos desarrollados podríamos afirmar que los símbolos no pueden ser definidos en términos precisos o unívocos tal como la ciencia social empírica-analítica ha podido pretender, ya que son fundamentalmente ambiguos, como hemos argumentado. Es necesario, por tanto, adoptar una postura epistemológica que tenga presente además del razonamiento lógico el potencial de la imaginación, el mito y lo simbólico, como condiciones esenciales de las formas de pensar, discurrir y vivenciar de los humanos. Sólo desde una perspectiva dialéctica y teniendo presente la coimplicación entre el pensamiento lógico y el simbólico es posible comprender la humanidad del hombre.

A este respecto y a la luz de nuestra propuesta es preciso no perder de vista el alcance de lo simbólico como condición estructural y de los símbolos en sí, en plural, como creadores de sentidos que deben ser interpretados en el marco de una cultura. En definitiva, no podemos olvidar el valor de lo simbólico en la comunicación, la creación del sentimiento de grupo o las identidades ya que las formas simbólicas se crean dentro de las comunidades humanas y funcionan como elementos de cohesión y crean ideología e imaginarios propios a cada comunidad. Y sólo mediante una hermenéutica simbólica es posible aproximarse a estos fenómenos de gran complejidad.

\section{Bibliografía}

Cassirer, E. 1963. Antropología filosófica: Introducción a una filosofía de la cultura. México: Fondo de Cultura Económica.

Cassirer, E. 1998. Filosofía de las formas simbólicas. El lenguaje, vol. 1. México: Fondo de Cultura Económica.

Chillón, A. 2000. La urdimbre mitopoética de la cultura. Anàlisi. Quaderns de Comunicació i Cultura 24: $121-159$.

Descartes, R. 1939. Discurso del método. Madrid: Editorial Espasa-Calpe.

Duch, L. 1974. Ciencia de la religión y mito: estudios sobre la interpretación del mito. Barcelona: Publicacions de I'Abadia de Montserrat.

Duch, L. 1978. Historia y estructuras religiosas. Barcelona: Ediciones Don Bosco.

Duch, L. 2002a. Mito, interpretación y cultura. Barcelona: Herder.

Duch, L. 2002b. Antropología de la vida cotidiana. Simbolismo y salud. Madrid: Trotta.

Duch, L. 2004. Estaciones del laberinto. Ensayos de antropología. Barcelona: Herder.

Duch, L. 2010. Religió i comunicació. Barcelona: Fragmenta Editorial.

Duch, L. y Chillón, A. 2012. Un ser de mediaciones. Antropología de la comunicación, vol. 1. Barcelona: Herder Editorial.

Gauchet, M. 2003. La religión de la democracia. El camino del laicismo. Barcelona: El cobre. 
Geertz, C. 1981. La interpretación de las culturas. Barcelona: Gedisa.

Jung, C. G. 1995. El hombre y sus símbolos. Barcelona: Paidós.

Mèlich, C. 1996. Antropología simbólica y acción educativa. Barcelona: Paidós.

Plessner, H. 1991. Conditio Humana. En: G. Mann y A. Heuss (Eds.) Historia Universal. Prehistoria. Las primeras culturas superiores, vol. 1. Madrid: Espasa-Calpe, 31-85.

Recibido el 14 Jul 2013

Aceptado el 2 Dic 2013 